\title{
Association Between the PIK3CA Ile391Met Polymorphism and the Risk of Breast Cancer in an Iranian Population
}

\author{
Salman Ahmadi ${ }^{1}$, Sina Ramezani ${ }^{2}$, Hossein Ghafouri' ${ }^{2}$, Sayed Mostafa Hosseini ${ }^{3}$, Ali Najafi ${ }^{1}$, Amir Homayoun Keihan ${ }^{1 *}$ \\ ${ }^{1}$ Molecular Biology Research Center, Systems Biology and Poisonings Institute, Baqiyatallah University of Medical Sciences, Tehran, \\ Iran \\ ${ }^{2}$ Department of Biology, Faculty of Science, University of Guilan, Rasht, Iran \\ ${ }^{3}$ Human Genetics Research Center, Baqiyatallah University of Medical Sciences, Tehran, Iran
}

Corresponding Author: Amir Homayoun Keihan, PhD in Biophysics, Assistant Professor, Molecular Biology Research Center, Systems Biology and Poisonings Institute, Baqiyatallah University of Medical Sciences, Tehran, Iran. Tel: +98-9124182758, Email: ahkeihan@bmsu.ac.ir

Received December 25, 2017; Revised February 4, 2018; Accepted February 15, 2018; Online Published March 30, 2018

\begin{abstract}
Introduction: Breast cancer, as a multifactorial disease is the most frequent cancer among women and second most commonly diagnosed cancer in worldwide. Breast cancer is associated with mutations in several genes such as PIK3CA. Phosphoinositide 3 kinase (PI3K) is an important group of lipid kinases that regulate the vital cellular functions such as survival, proliferation, cell growth, motility, differentiation, and intracellular trafficking. The aim of this study is to evaluate the association of rs2230461 of PIK3CA gene with the incidence of breast cancer.

Materials and Methods: A total of 198 healthy donors and 205 breast cancer patients were recruited. Genomic DNA was extracted from peripheral blood leukocytes by Triton X100 technique. Genotyping was performed using RFLP-PCR protocol. Chi-square test, odds ratios (ORs) and 95\% Cls were used to determine associations.

Results: There were no significant differences observed regarding the PIK3CA genotype frequencies at codon 391 between patient and control groups $(P=0.17)$. However, by comparing stage III breast cancer patients and control groups, there was a significantly higher frequency of the GG genotype among stage III cases compared to control $(P=0.01)$. Although the PIK3CA I391M polymorphism has been located in the C2 domain and doesn't involve in the binding site, it can affect the protein function.

Conclusions: Since even those mutations that are far from the binding site can affect the protein function and change its dynamic behavior through allosteric impacts and lead to tumorigenesis at last. Since PIK3CA mutations mainly appear late in tumorigenesis, exactly before or coincident with invasion, and may be involved in tumor formation, it is suggested that this polymorphism may be involved in breast cancer invasion. Keywords: PIK3CA, Polymorphism, Breast Cancer

Citation: Ahmadi S, Ramezani S, Ghafouri H, Hosseini SM, Najafi A, Keihan AH. Association between the PIK3CA Ile391Met polymorphism and the risk of breast cancer in an Iranian population. J Appl Biotechnol Rep. 2018;5(1):8-12. doi:10.29252/jabr.01.01.02.
\end{abstract}

\section{Introduction}

Breast cancer, as a multifactorial disease is the most frequent cancer among women and second most commonly diagnosed cancer in worldwide. According to reports from the International Agency for Research on Cancer (IARC), there are 1.67 million breast cancer diagnosed in 2012 (25\% of all cancers) with about 522000 death reports. ${ }^{1,2}$ The incidence of breast cancer in the last 30 years has been up trended in many countries. Epidemiologic studies suggest the important role of environmental and genetic factors in the development of breast cancer. ${ }^{3,4}$ The incidence rates of breast cancer in all over the world reported as follows: highest in North America (age-standardized rate [ASR]: 123.6 per 100000$)^{5}$ and Western Europe (ASR: 84.6 per 100000$),{ }^{3}$ intermediate in the Mediterranean and South American countries (ASR: 46 per $100000)^{4}$ and lowest in Southeast (ASR: 25.5 per 100000$)^{4,6}$ and South Central Asia (ASR: 21.8 per 100000$).{ }^{6}$ Breast cancer is ranked first among malignancies in Iranian women, ${ }^{7,8}$ comprising $24.4 \%$ of all cancers ${ }^{9}$ with a crude incidence rate of 17.81 and an ASR of 23.65 in the year of $2006 .{ }^{8}$ According to the new statistic, 6160 breast cancers are diagnosed in Iran each year, which 1063 cases of them lead to death. ${ }^{10,11}$ According to the report of World Health Organization (WHO), the incidence of breast cancer has annually increased by $2 \% .{ }^{12} \mathrm{~A}$ portion of this increase is related to changes in reproductive patterns, such as delayed childbearing and having fewer children. ${ }^{13}$ The crude rate and ASR of breast cancer incidence in the Iranian women were increased respectively from 12.19 and 15.96 in 2003 to 22.09 and 28.25 in 2009 per $100000 .{ }^{14}$ Although the incidence of breast cancer in Asian women is lower than women in Western countries, its incidence trend is higher than Western countries. Breast cancer is happening

Copyright (C) 2018 The Author(s). This is an open-access article distributed under the terms of the Creative Commons Attribution License (http:// creativecommons.org/licenses/by/4.0), which permits unrestricted use, distribution, and reproduction in any medium, provided the original work is properly cited. 
in the Iranian women at least a decade earlier than women in developed countries and most of the patients are in the age of 40-49 years old in Iran. ${ }^{15}$ Breast cancer has four stages. The stage 0 are non-invasive cancers that remain in initial location and stage IV are invasive cancers that have spread to other parts of the body. ${ }^{16}$ With the completion of the Human Genome Project (HGP), single nucleotide polymorphisms (SNPs) regarded as an essential factor in the development of different cancers. ${ }^{17,18}$ Each SNP that has been known to date only have a small relative risk on their own, but altogether, they can provide an accurate assessment of the risk of breast cancer in the general population. ${ }^{19}$ It is reported that at least 94 common breast risk SNPs have associated with breast cancer ${ }^{20}$ Breast cancer is associated with mutations in several genes such as BRCA1, BRCA2, CDH1, PIK3CA and TP53. ${ }^{21}$ Phosphoinositide 3 kinase (PI3K) is an important group of lipid kinases that regulate the vital cellular functions such as survival, proliferation, cell growth, motility, differentiation, and intracellular trafficking. PI3K is divided into 3 classes (I-III) based on their primary structure and lipid substrate specificity. Class I PI3K are heterodimers that further classified into class IA and IB. Among all PI3K classes, class IA has the most closely implicated in cancer and comprise a p 110 catalytic subunit and a p85 regulatory subunit. P110a (encoded by PIK3CA), is one of the 3 isoforms of p110 subunit. ${ }^{22}$ After the TP53, PIK3CA is found to be the second most predominant gene with mutations in breast cancer which the rate of its mutation is $16.4 \%$ to $45 \%{ }^{21,23} \mathrm{PI} 3 \mathrm{~K} / \mathrm{Akt} / \mathrm{mammalian}$ target of rapamycin (mTOR) is a main intracellular signaling pathway, which is frequently activated in breast cancer. PI3K/Akt/ mTOR responds to the accessibility of hormones, nutrients, and growth factor stimulation. The central role of this pathway in tumor cell growth and proliferation is played by Class IA PI3K. ${ }^{24}$ Mutations in the PIK3CA affects downstream pathways. So that they are often causing the dysregulate of $\mathrm{PI} 3 \mathrm{~K} / \mathrm{AKT} / \mathrm{mTOR}$ signaling pathway and have been reported in various human cancers such as breast cancer. ${ }^{25}$

The aim of this study is to evaluate the association of rs2230461 of PIK3CA gene with the incidence of breast cancer. The rs2230461 is a missense polymorphism which causes the replacement of isoleucine to methionine at codon 391. To the best of our knowledge, this is the first time that the association of rs2230461 with breast cancer incidence has been studied.

\section{Materials and Methods}

Sampling

Peripheral blood samples were collected from 198 healthy donors, aged between 35 and 55 years old (control cases) and 205 breast cancer patients. All volunteers, who met the inclusion criteria for participating in this study, were Iranian who resided in Guilan province. The ethics approval was performed based on the Iranian ministry of health and medical education criteria. To prevent from any biased sampling, all samples were collected randomly, without any discriminatory information about her families, social and histopathological background of the subject. Normal blood samples were collected from women examined at Razi hospital, Rasht, Iran.
Genomic DNA Isolation

DNA was extracted from peripheral blood leukocytes by Triton X100 technique. The extracted DNA was diluted in 100 $\mu \mathrm{L}$ deionized water and it was kept at $-20^{\circ} \mathrm{C}$ until use.

\section{Genotyping}

Initially, the upstream and downstream flanking regions of rs2230461 were taken from National Center for Biotechnology Information (NCBI). RFLP PCR primers were designed by using the Oligo7 software. To avoid the formation of stable primer-dimers, the primers were accurately assessed by NCBI/Primer-BLAST online software. The forward and reverse primer sequences are 5' ATAACCTTACCACCCCTT $3^{\prime}$ and 5' AGCGGTATAATCAGGAGT 3' respectively. RFLP PCR was performed using about $40 \mathrm{ng}$ genomic DNA, 2 pmol of each primer and $7.5 \mu \mathrm{L}$ of Ampliqon Taq DNA Polymerase Master Mix in a total volume of $15 \mu \mathrm{L}$. After performing the gradient temperature, the best-optimized condition was as follow: the initial denaturation step at $95^{\circ} \mathrm{C}$ for 5 minutes, 30 cycles constituting the denaturation in $95^{\circ} \mathrm{C}$ for 30 seconds, annealing in $56^{\circ} \mathrm{C}$ for 30 seconds, the elongation in $72^{\circ} \mathrm{C}$ for 30 seconds, followed by a final elongation step at $72^{\circ} \mathrm{C}$ for 5 minutes. The length of PCR product was $451 \mathrm{bp}$ which separated using $2 \%$ agarose gel electrophoresis and safe stain staining.

After ensuring sample amplifications on the agarose gel, the 451 bp PCR products were digested using 1 unit of BsrG1 restriction enzyme (Thermo Scientific, American) at $37^{\circ} \mathrm{C}$ for 2 hours. To determine the genotypes, digested PCR products were separated using $2 \%$ agarose gel electrophoresis and safe stain staining once again. The wild-type allele (Ile), which has no BsrG1 restriction enzyme site, revealed as a single fragment of $451 \mathrm{bp}$ and is indicative of the homozygous wildtype (AA) genotype, while the homozygous mutant genotype (GG) generates two fragments of 313 and $138 \mathrm{bp}$, and lastly the heterozygous genotype (AG) contains all 3 fragments of 451,313 and $138 \mathrm{bp}$. To confirm the accuracy of genotyping results, twenty samples including 15 homozygotes and 5 heterozygotes, were randomly selected and re-genotyped using the same method.

\section{Statistical Analysis}

The allele frequency within each group was determined as the number of occurrences of an individual allele divided by the total number of alleles. To determine whether any significant differences in polymorphism frequencies occurred between the case and control population, allele and genotype frequencies were compared using the chi-square method and the MedCalc version 9.6.4.0. Odds ratio (OR) and 95\% CIs were calculated to determine the risk of breast cancer associated with a given PIK3CA genotype. $P$ values of less than or equal to 0.05 were considered to represent statistical significance.

\section{Ethical Considerations}

All individuals participated in the current study were consented in a process approved by the Ethics Committee for Human Genome/Gene Research at the University of Guilan 


\section{(NO. IR.BMSU.REC.1396.443).}

Results

\section{Participants Information}

This case-control study included 198 breast cancer patients and 205 healthy individuals. The breast cancer patients' age ranged between 35 and 55 years.

\section{Genotyping}

A partial fragment of the PIK3CA gene that contained SNP rs2230461was amplified using by PCR. A PCR product of $451 \mathrm{bp}$ was detected by running aliquots of the PCR product on $2 \%$ agarose gel electrophoresis. No enzymatic restriction occurred in AA genotype and a 451bp fragment was obtained. The 313 and 138 base pair bands were seen in GG genotype and 313,138 and 451 base pair bands were obtained in AG genotype (Figure 1). Also, the frequency of the rs2230461 polymorphism of PIK3CA gene was analyzed.

\section{Data Analysis}

All information about allele and genotype frequencies and related ORs (95\% CI) for patients and controls have been shown in Table 1. There were no significant differences observed regarding the PIK3CA genotype frequencies at codon 391 between patient and control groups $(P=0.17)$. However, a genotype-phenotype subanalysis of cancer stages was done on 52 out of 195 breast cancer patients who were at stage III. by comparing stage III breast cancer patients and control groups, there was a significantly higher frequency of the GG genotype among stage III cases compared to control $(P=0.01)$. (table is not shown). Moreover, AG genotype seems to be the risk factor in a co-dominant model of hereditary between case and control groups $(P=0.006$, OR $4.3,95 \%$ CI 1.5-12.24).

\section{Discussion}

PI3K is an important group of lipid kinases that regulate the vital cellular functions such as proliferation, cell growth, motility, differentiation, and intracellular trafficking. Also, previous studies have shown that PIK3CA is a key factor in the survival of tumor cells. ${ }^{22} \mathrm{PI} 3 \mathrm{~K} / \mathrm{Akt} / \mathrm{mammalian}$ target of rapamycin (mTOR) is a main intracellular signaling pathway, which is frequently activated in breast cancer. PI3K/Akt/ mTOR responds to the accessibility of hormones, nutrients, and growth factor stimulation. ${ }^{24}$ To the best of our knowledge,

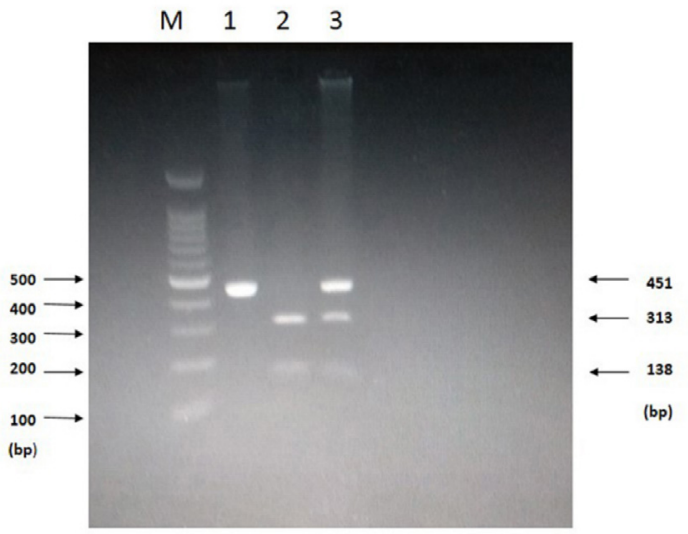

Figure 1. RFLP Analysis of the Polymorphism. Lane 1: undigested PCR product of 451 Ile/lle genotype, lane 2: two fragments of 313 and $138 \mathrm{bp}$ for Met/Met genotype, lanes 3: three fragments of 451,313 and $138 \mathrm{bp}$ for Ile/Met genotype. M: molecular size marker.

this is the first study on the PIK3CA I391M polymorphism and the risk of breast cancer incidence. The PI3K/AKT signaling pathway was frequently activated by gene mutations. ${ }^{26}$ Moreover, genetic polymorphisms of PIK3CA were also reported to be related with breast cancer, headneck squamous cell carcinoma, esophageal squamous cell carcinoma, non-small cell lung cancer, endometrial cancer, gastric cancer and rectal cancer. ${ }^{27-33}$ PI3K comprise two major subunits, a catalytic subunit p110 and a regulatory subunit p85. ${ }^{34}$ The regulatory subunit has two major roles: they stabilize the catalytic subunit against thermal denaturation, and they maintain the catalytic subunit in an inhibited, low activity state. ${ }^{35,36} \mathrm{p} 85$ and $\mathrm{p} 110$ are both multidomain proteins that bind to each other and to upstream activators. ${ }^{37} \mathrm{C} 2$-iSH2 is a communication interface that is required for inhibition of $\mathrm{p} 110 \mathrm{a}$ by $\mathrm{p} 85$. Mutations that particularly disrupt the $\mathrm{C} 2$-iSH2 contact, led to loss of p110a inhibition. Even those $\mathrm{PI} 3 \mathrm{Ka}$ mutations that are located far from the active site and which increase the enzymatic activity are associated with changes in the dynamic behavior of the protein in a large-scale. In other words, these mutations have allosteric impacts on the protein. ${ }^{38-41} \mathrm{~A}$ significant connection between the PIK3CA and association of age in women with breast cancer has been reported. ${ }^{34}$ Specifically, mutations in the catalytic subunit, upregulate $\mathrm{PI} 3 \mathrm{~K} / \mathrm{AKT} / \mathrm{mTOR}$ pathway and promote carcinogenesis providing a way for the development

Table 1. Genotype Frequencies of PIK3CA Ile391Met Polymorphism Among Breast Cancer Cases and Controls

\begin{tabular}{|c|c|c|c|c|c|}
\hline Genetic Models & Genotype & $\begin{array}{l}\text { Patients } \\
\text { No. }(\%)\end{array}$ & $\begin{array}{l}\text { Controls } \\
\text { No. }(\%)\end{array}$ & $\begin{array}{c}\text { OR } \\
(95 \% \mathrm{CI})\end{array}$ & $P$ Value \\
\hline PIK3CA & Ile/lle & 36 & 117 & 1.00 & \\
\hline Ile391Met & Ile/Met & 8 & 9 & $4.3(1.5-12.24)$ & 0.006 \\
\hline Codominant & Met/Met & 8 & 22 & $0.98(0.42-2.30$ & 0.97 \\
\hline \multirow{2}{*}{ Dominant } & Ile/lle & 36 & 117 & 1.00 & \\
\hline & Ile/Met+Met/Met & 16 & 31 & $1.60(0.81-3.15)$ & 0.17 \\
\hline Recessive & Met/Met & 8 & 22 & $0.55(0.24-1.26)$ & 0.16 \\
\hline \multirow{2}{*}{ Overdominant } & Ile/Ile+Met/Met & 44 & 139 & 1.00 & \\
\hline & Ile/Met & 8 & 9 & $4.3(1.53-12.13)$ & 0.005 \\
\hline
\end{tabular}


of PI3K inhibitors toward cancer therapy. Even on the basis of mutations severity, several drugs were designed to inhibit PI3K-AKT-mTOR pathway for cancer therapy. ${ }^{42}$

In a previous study, Karakas et al studied the prevalence of PIK3CA mutations and the SNP rs17849073 in Arab breast cancer patients among 81 breast cancer tissues and 189 blood sample of the healthy donors. They found a total of 21 PIK3CA missense mutations with $25.9 \%$ frequency. PIK3CA mutations were significantly associated with lower grade and hormone receptor positivity. Also, they identified a high prevalence of the SNP rs7849073 in the Arab breast cancer population compared to the healthy group. Karakas et al showed the importance of PIK3CA mutation and polymorphism in susceptibility to breast cancer incidence. ${ }^{43}$ In another study, Mir et al investigated the PIK3CA rs7640662 polymorphism association with breast cancer in a Persian population with 278 breast cancer patients and 128 healthy women. Mir et al did not observe any significant association between the rs7640662 and breast cancer incidence $(P>0.05)$. However, their results showed no association between the rs7640662 and breast cancer incidence further research is needed based on larger sample size and in different ethnic population to realize the impact of $P I K 3 C A$ rs7640662 on breast cancer incidence. $^{44}$

In the current study, the PIK3CA I391M polymorphism was investigated in a series of 205 breast cancer patients and 198 population matched controls in order to verify the impact of PIK3CA variant on the risk of tumor development in Iranian breast cancer patients. Our results showed significant differences in the genotype distribution of the PIK3CA I391M polymorphism between stage III breast cancer patients and controls $(P=0.01)$. AG genotype was significantly associated with the presence of breast cancer $(P=0.006$, OR $4.3,95 \%$ CI 1.5-12.24). Although the PIK3CA I391M polymorphism has been located in the $\mathrm{C} 2$ domain and doesn't involve in the binding site, it can affect the protein function and finally lead to cancer. Since even those mutations that are far from the binding site can affect the protein function and change its dynamic behavior. On the other hand, a study has revealed that PIK3CA mutations mainly appear late in tumorigenesis, exactly before or coincident with invasion and demonstrating that PIK3CA may be closely related to the invasiveness of cancer cells. Furthermore, PIK3CA polymorphisms caused improvement of the PI $3 \mathrm{~K}$ signaling pathway in tumor tissues, that likewise suggested PIK3CA may be involved in tumor formation..$^{27,30}$ Since in our study, the PIK3CA I391M polymorphism, had only a significant relation with stage III breast cancer, it is suggested that this polymorphism may be involved in breast cancer invasion.

\section{Conclusions}

To the best of our knowledge, this case-control study for the first time studied the association of PIK3CA I391M polymorphism and susceptibility to breast cancer. In this population based on the breast cancer in Guilan, Iran, it has been demonstrated that the genetic polymorphism in PIK3CA gene ( $r 2230461 \mathrm{~A}>\mathrm{G}$ ) is not associated with the risk of breast cancer incidence. However, significant differences observed in stage III patients can be a molecular sign that reveals the PIK3CA rs2230461 may be closely related to the beginning of invasion in breast cancer cells. To make ensure, it is suggested that these structural variants in other populations with larger sample size to be investigated too. In addition, the rs2230461 and such these structural variants might be potential SNP markers for tumorigenesis of breast cancer which suggest genotyping of structural variants in drug designing and prescription of related drugs according to personal genotypes.

\section{Authors' Contributions}

All Authors contributed equally to this research.

\section{Conflict of Interest Disclosures}

The authors declare they have no conflicts of interest.

\section{Acknowledgments}

The authors would like to acknowledge all of their colleagues in the Molecular Biology Research Center, Systems Biology and Poisonings Institute, Baqiyatallah University of Medical Sciences, Tehran, Iran, for their help.

\section{References}

1. Comprehensive molecular portraits of human breast tumours Nature. 2012;490(7418):61-70. doi:10.1038/nature11412.

2. Ferlay J, Soerjomataram I, Dikshit R, et al. Cancer incidence and mortality worldwide: sources, methods and major patterns in GLOBOCAN 2012. Int J Cancer. 2015;136(5):E359-386. doi:10.1002/ijc.29210.

3. Chen F, Zhou J, Xue Y, et al. A single nucleotide polymorphism of the TNRC9 gene associated with breast cancer risk in Chinese Han women. Genet Mol Res. 2014;13(1):182-187. doi:10.4238/2014. January.10.9.

4. Parkin DM, Bray F, Ferlay J, Pisani P. Global cancer statistics, 2002. CA Cancer J Clin. 2005;55(2):74-108.

5. Jemal A, Siegel R, Ward E, Hao Y, Xu J, Thun MJ. Cancer statistics, 2009. CA Cancer J Clin. 2009;59(4):225-249. doi:10.3322/ caac.20006.

6. Parkin DM, Whelan SL, Ferlay J, Teppo L, Thomas DB. Cancer incidence in five continents. Volume VIII. IARC Sci Publ. 2002(155):1-781.

7. Sadjadi A, Nouraie M, Mohagheghi MA, Mousavi-Jarrahi A, Malekezadeh R, Parkin DM. Cancer occurrence in Iran in 2002, an international perspective. Asian Pac J Cancer Prev. 2005;6(3):359363.

8. Mousavi SM, Gouya MM, Ramazani R, Davanlou M, Hajsadeghi $\mathrm{N}$, Seddighi Z. Cancer incidence and mortality in Iran. Ann Oncol. 2009;20(3):556-563. doi:10.1093/annonc/mdn642.

9. Goya M. Iranian Annual Cancer Registration Report 2005/2006. Tehran: Ministry of Health and Medical Education, Health Deputy, Center for Disease Control and Prevention; 2007.

10. Alizadeh Otaghvar HR, Hoseini M, Mirmalek A, Ahmari H, Arab F, Mohtasham Amiri N. Breast Sarcoma: a review article. Iran J Surg. 2014;22(1):1-11

11. Mousavi SM, Montazeri A, Mohagheghi MA, et al. Breast cancer in Iran: an epidemiological review. Breast J. 2007;13(4):383-391. doi:10.1111/j.1524-4741.2007.00446.x.

12. Henderson IC, Canellos GP. Cancer of the breast: the past decade (first of two parts). N Engl J Med. 1980;302(1):17-30. doi:10.1056/ nejm198001033020104.

13. Goya M. Iranian annual cancer registration report. Tehran: Ministry of Health and Medical Education, Health Deputy, Center for Disease Control and Prevention; 2005.

14. Sharifian A, Pourhoseingholi MA, Emadedin M, et al. Burden of 
Breast Cancer in Iranian Women is Increasing. Asian Pac J Cancer Prev. 2015;16(12):5049-5052.

15. Shibuya K, Mathers CD, Boschi-Pinto C, Lopez AD, Murray CJ. Global and regional estimates of cancer mortality and incidence by site: II. Results for the global burden of disease 2000. BMC Cancer. 2002;2:37.

16. Moran MS, Schnitt SJ, Giuliano AE, et al. Society of Surgical Oncology-American Society for Radiation Oncology consensus guideline on margins for breast-conserving surgery with wholebreast irradiation in stages I and II invasive breast cancer. Int J Radiat Oncol Biol Phys. 2014;88(3):553-564. doi:10.1016/j. ijrobp.2013.11.012.

17. Han W, Woo JH, Yu JH, et al. Common genetic variants associated with breast cancer in Korean women and differential susceptibility according to intrinsic subtype. Cancer Epidemiol Biomarkers Prev. 2011;20(5):793-798. doi:10.1158/1055-9965.epi-10-1282.

18. Li Y, Song D, Jiang $Y$, et al. CR1 rs3818361 Polymorphism Contributes to Alzheimer's Disease Susceptibility in Chinese Population. Mol Neurobiol. 2016;53(6):4054-4059. doi:10.1007/ s12035-015-9343-7.

19. Brentnall AR, Evans DG, Cuzick J. Distribution of breast cancer risk from SNPs and classical risk factors in women of routine screening age in the UK. Br J Cancer. 2014;110(3):827-828. doi:10.1038/ bjc.2013.747.

20. Cuzick J, Brentnall AR, Segal C, et al. Impact of a Panel of 88 Single Nucleotide Polymorphisms on the Risk of Breast Cancer in High-Risk Women: Results From Two Randomized Tamoxifen Prevention Trials. J Clin Oncol. 2017;35(7):743-750. doi:10.1200/ jco.2016.69.8944.

21. Kumar DT, Doss CG. Investigating the Inhibitory Effect of Wortmannin in the Hotspot Mutation at Codon 1047 of PIK3CA Kinase Domain: A Molecular Docking and Molecular Dynamics Approach. Adv Protein Chem Struct Biol. 2016;102:267-297. doi:10.1016/bs.apcsb.2015.09.008.

22. Liu P, Cheng H, Roberts TM, Zhao JJ. Targeting the phosphoinositide 3-kinase pathway in cancer. Nat Rev Drug Discov. 2009;8(8):627644. doi:10.1038/nrd2926.

23. Mangone FR, Bobrovnitchaia IG, Salaorni S, Manuli E, Nagai MA. PIK3CA exon 20 mutations are associated with poor prognosis in breast cancer patients. Clinics (Sao Paulo). 2012;67(11):12851290.

24. Cantley LC. The phosphoinositide 3-kinase pathway. Science. 2002;296(5573):1655-1657. doi:10.1126/science.296.5573.1655.

25. Samuels Y, Wang Z, Bardelli A, et al. High frequency of mutations of the PIK3CA gene in human cancers. Science. 2004;304(5670):554. doi:10.1126/science.1096502.

26. Cohen Y, Goldenberg-Cohen N, Shalmon B, et al. Mutational analysis of PTEN/PIK3CA/AKT pathway in oral squamous cell carcinoma. Oral Oncol. 2011;47(10):946-950. doi:10.1016/j. oraloncology.2011.07.013.

27. Lin DC, Hao JJ, Nagata $Y$, et al. Genomic and molecular characterization of esophageal squamous cell carcinoma. Nat Genet. 2014;46(5):467-473. doi:10.1038/ng.2935.

28. Pang B, Sun SP, Gao L, et al. A single nucleotide polymorphism in PIK3CA gene is inversely associated with P53 protein expression in breast cancer. Med Oncol. 2014;31(7):30. doi:10.1007/s12032014-0030-8.

29. Pu X, Hildebrandt MA, Lu C, et al. PI3K/PTEN/AKT/mTOR pathway genetic variation predicts toxicity and distant progression in lung cancer patients receiving platinum-based chemotherapy. Lung Cancer. 2011;71(1):82-88. doi:10.1016/j.lungcan.2010.04.008.

30. Rivera M, Ricarte-Filho J, Patel S, et al. Encapsulated thyroid tumors of follicular cell origin with high grade features (high mitotic rate/tumor necrosis): a clinicopathologic and molecular study. Hum Pathol. 2010;41(2):172-180. doi:10.1016/j. humpath.2009.08.011.

31. Slattery ML, Herrick JS, Lundgreen A, Fitzpatrick FA, Curtin K, Wolff RK. Genetic variation in a metabolic signaling pathway and colon and rectal cancer risk: mTOR, PTEN, STK11, RPKAA1, PRKAG2, TSC1, TSC2, PI3K and Akt1. Carcinogenesis. 2010;31(9):16041611. doi:10.1093/carcin/bgq142.

32. Wan X, Li X, Yang J, et al. Genetic association between PIK3CA gene and oral squamous cell carcinoma: a case control study conducted in Chongqing, China. Int J Clin Exp Pathol. 2015;8(10):13360-13366.

33. Wang LE, Ma H, Hale KS, et al. Roles of genetic variants in the PI3K and RAS/RAF pathways in susceptibility to endometrial cancer and clinical outcomes. J Cancer Res Clin Oncol. 2012;138(3):377385. doi:10.1007/s00432-011-1103-0.

34. Firoozinia $M$, Zareian Jahromi $M$, Moghadamtousi SZ, Nikzad $\mathrm{S}$, Abdul Kadir H. PIK3CA gene amplification and PI3K p110alpha protein expression in breast carcinoma. Int J Med Sci. 2014;11(6):620-625. doi:10.7150/ijms.8251.

35. Kodaki T, Woscholski R, Hallberg B, Rodriguez-Viciana P, Downward J, Parker PJ. The activation of phosphatidylinositol 3-kinase by Ras. Curr Biol. 1994;4(9):798-806.

36. Yu J, Zhang Y, Mcllroy J, Rordorf-Nikolic T, Orr GA, Backer JM. Regulation of the p85/p110 phosphatidylinositol 3'-kinase: stabilization and inhibition of the p110alpha catalytic subunit by the p85 regulatory subunit. Mol Cell Biol. 1998;18(3):1379-1387.

37. Wu H, Yan Y, Backer JM. Regulation of class IA PI3Ks. Portland Press Limited; 2007.

38. Cooper A, Dryden DTF. Allostery without conformational change. Eur Biophys J. 1984;11(2):103-109. doi:10.1007/bf00276625.

39. Motlagh HN, Wrabl JO, Li J, Hilser VJ. The ensemble nature of allostery. Nature. 2014;508(7496):331-339. doi:10.1038/ nature 13001

40. Nussinov R, Ma B. Protein dynamics and conformational selection in bidirectional signal transduction. BMC Biol. 2012;10:2. doi:10.1186/1741-7007-10-2.

41. Tsai CJ, Del Sol A, Nussinov R. Protein allostery, signal transmission and dynamics: a classification scheme of allosteric mechanisms. Mol Biosyst. 2009;5(3):207-216. doi:10.1039/b819720b.

42. Nylander S, Kull B, Bjorkman JA, et al. Human target validation of phosphoinositide 3-kinase (PI3K)beta: effects on platelets and insulin sensitivity, using AZD6482 a novel PI3Kbeta inhibitor. J Thromb Haemost. 2012;10(10):2127-2136. doi:10.1111/j.15387836.2012.04898.x.

43. Karakas B, Colak D, Kaya N, et al. Prevalence of PIK3CA mutations and the SNP rs17849079 in Arab breast cancer patients. Cancer Biol Ther. 2013;14(10):888-896. doi:10.4161/cbt.25945.

44. Mir A, Sadegh MH, Ahmadinia Z, Kaboli PJ. PIK3CA rs7640662 (C/G) single nucleotide polymorphism lacks association with breast cancer cases in Persians. Interv Med Appl Sci. 2015;7(1):38. doi:10.1556/imas.7.2015.1.1. 